\title{
Identification of red grape varieties by anthocyanin profile
}

\author{
Veronica Andreeva* \\ Federal State Budget Educational Institution of Higher Education "Platov South-Russian State \\ Polytechnic University (NPI)”, 132, Prosveshcheniya str., Novocherkassk, 346428, Russia
}

\begin{abstract}
The presence of anthocyans was studied to determine the anthocyanin profile as a tool for distinguishing grapes of the Don region of autochthonous and hybrid varieties of ARRIVW breeding and other hybrid varieties for isolation and identifying typical characteristics. The composition of anthocyans depends on both the variety and the grape habitat. The presence of 3.5-diglucosides in hybrid varieties was established.
\end{abstract}

\section{Introduction}

The achievements of viticulture and winemaking are aimed at promoting new varieties for cultivation in more northern territories. Along with recommendations on agricultural techniques, maturation periods and technological direction, hybrid varieties should be accompanied by a description of varietal quality parameters. The resulting new hybrid grape varieties are difficult to distinguish due to the large variability of morphological characteristics. Since the beginning of the 20th century, rootstocks imported from North America have been widely used in Europe to give a certain resistance against phylloxera to European varieties of the Vitis vinifera L. species [1,2]. This led to the emergence of adapted varieties that restored lost plantings after the phylloxera outbreak in Europe. Also, operations of crossing grapes of other species (Vitis labrusca L., Vitis amurensis Rupr., etc.) allowed to obtain new varieties that are resistant to diseases, low temperatures and other factors. However, this crossing leads to the change in the anthocyanin profile: 3-glycosides of anthocyanidins are supplemented with 3,5-diglucosides.

The anthocyanin composition of grapes is one of the main criteria for determining its authenticity. Anthocyans belong to the group of phenolic compounds, where they are coloring compounds. Tannins adds a palatefullness. Coloring compounds and tannins, as well as the products of their transformations, affect the aroma, taste, color and limpidity of juices and wines.

"Anthocyans" - this designation is used in Russian literature, it is more informative to refer to the term "anthocyanins", "anthocyanin profile". During studying of the red hybrid forms of grapes NCZSRIHV breeding, it was found that anthocyans and phenolic compounds accumulate at the beginning of fruiting and are found in wine materials, this grapes hybrids contain the largest number of phenolic compounds $\left(3600-4400 \mathrm{mg} / \mathrm{dm}^{3}\right)$ and are differed by high tasting ratings [3].

*Corresponding author: veronica.andreeva@gmail.com 
However, in accordance with EU regulations, wine for commercial purposes can only be produced from thoroughbred varieties of $V$. vinifera and certain crosses of $V$. vinifera with certain other selected species of the genus Vitis L. (European community regulation (CE) № 479,2008 ) [4]. By studying the varietal characteristics of hybrid grape varieties, we get new information about the possibility of their use and of obtaining high-quality wines.

The purpose of the research was to study the chromatographic profiles of anthocyans in the berries skin of red grape varieties growing in the Rostov region (autochthonous varieties and varieties of ARRIVW breeding).

\section{Materials and methods}

The objects of research are grapes of the following varieties: Tsimlyansky Cherny, Krasnostop Zolotovsky (Don autochthonous varieties), Cabernet Sauvignon, Hamburg Muscat Vitis vinifera L., Cabernet Severny ((Galan x Vitis amurensis) x pollen mixture of European-Amur hybrid forms), ARRIVW), Fioletovy Rannij (Severny (Malengra Seedling $\mathrm{x}$ Vitis amurensis) x Hamburg Muscat, ARRIVW), Denisovsky (Severny x Muscat pollen mixture, ARRIVW), Moldova (Guzal Cara x Villard Blanc, "Vierul"), Isabella (Vitis labrusca).

The grapes were harvested during the period of technical maturity, physical and chemical parameters were determined according to standardized methods operating on the territory of the Russian Federation. In the studied grape varieties, the skin was separated and anthocyans were extracted with an aqueous 0.1 mol solution of hydrochloric acid. Before chromatography, the extracts were purified from accompanying extractives by solid-phase extraction using DIAPAK C18 concentrating cartridges (BioChimMak ST, Moscow): sorption was performed from the extract in 0.1 mol aqueous $\mathrm{HCl}$ solution, and a solution containing 30 vol.. \% acetonitrile and 30 vol. \% formic acid in water was used for desorption of anthocyans. The resulting solution was diluted three times with distilled water before being introduced into the chromatographic system.

The studies were performed on an Agilent 1260 chromatograph with diode-matrix and mass-spectrometric detectors. Water-acetonitril solutions acidified with formic acid of the acetonitrile - formic acid - water composition in isocratic or gradient modes were used as eluents. The components were separated on a chromatographic column $4.6 \times 250 \mathrm{~mm}$ Symmetry ${ }^{\circledR} \mathrm{C} 18,5$ microns, at a temperature of $40{ }^{\circ} \mathrm{C}$. The flowrate of the mobile phase is $1 \mathrm{ml} / \mathrm{min}$. Detection wavelength: $515 \mathrm{~nm}$. The spectra of individual components are recorded in the cell of a diode matrix detector in the range of 420-600 Anthocyans were identified using an Agilent 6130 quadrupole mass spectrometer with electrospray ionization.

\section{Results and Discussion}

Anthocyans and flavonols are important metabolites of flavonoids in grapes, which make a dominant contribution to the color, mouthfeel, and taste of grapes and wines. The accumulation of these compounds in grapes is largely dependent on a variety of diverse and interacting factors, of which the variety of crossing combinations and climatic conditions are among the most important.

To confirm the varietal authenticity of red wines produced in Chile, the ratio of acetylated/coumaroylated anthocyans (Rac/cum) is proposed. By the value of the Rac/cum ratio and the mass concentration of shikimic acid, wines from Cabernet Sauvignon grapes can be distinguished from Carmenere and Merlot wines. Wines from the Carmenere and Merlot grape varieties can be distinguished by the quercetin/myricetin ratio in combination with peonidin-3-glycoside [4]. The composition of grape anthocyans is genetically 
determined, but grape processing and winemaking technology (processing with enzyme preparations, thermovinification temperature, contact time of the liquid and solid phases of the pomance, etc.) have a significant impact on the ratio of various anthocyans and identification criteria based on anthocyanin profiles, which must be taken into account when checking the varietal affiliation of wines [5].

Flavonoids of red grape varieties are mainly a group of compounds with a carbon skeleton C6-C3-C6, consisting of two aromatic rings and one heterocyclic oxygen-containing pyran ring. In plant raw materials, flavonoids are in the free state, i.e. in the form of aglycons, and in the carbohydrate-bound state, i.e. in the form of glycosides. Glycosides exhibit biological activity. These compounds are able to form various derivatives due to the introduction of the following groups into the aromatic rings: - $\mathrm{OH}$,- OCH3, - CH3 (Figure 1). Grape anthocyans are mainly represented by five aglycons: delphinidin $(\mathrm{Dp})$, cyanidin $(\mathrm{Cy})$, petunidin $(\mathrm{Pt})$, peonidin $(\mathrm{Pn})$, and malvidin $(\mathrm{Mv})$, which can be either 3-OH monoglucosylated or 3,5-OH diglucosylated [6]. These compounds are colored by the name of the plants in whose colors they are found: red, blue, purple, blue.

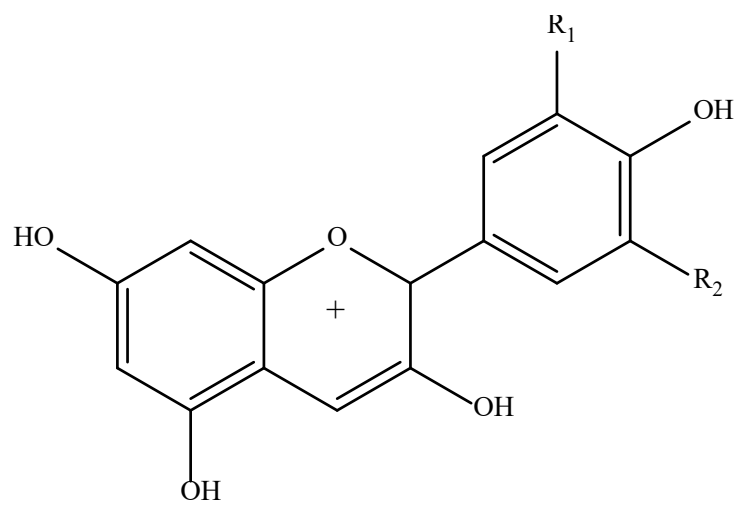

Pelargonidin $\left(\mathrm{R}_{1}=\mathrm{R}_{2}=\mathrm{H}\right)$; cyanidin $(\mathrm{Cy})\left(\mathrm{R}_{1}=\mathrm{OH} ; \mathrm{R}_{2}=\mathrm{H}\right)$; peonidin $(\mathrm{Pn})\left(\mathrm{R}_{1}=\mathrm{R}_{2}=\mathrm{H}\right)$; delphinidin (Dp) $\left(\mathrm{R}_{1}=\mathrm{OCH}_{3} ; \mathrm{R}_{2}=\mathrm{H}\right)$; petunidin $(\mathrm{Pt})\left(\mathrm{R}_{1}=\mathrm{OH} ; \mathrm{R}_{2}=\mathrm{OCH}_{3}\right) ;$ malvidin $(\mathrm{Mv})\left(\mathrm{R}_{1}=\mathrm{R}_{2}=\mathrm{OCH}_{3}\right)$

Fig. 1. Structure of anthocyanidins.

Currently, for identification several molecular approaches are available to differentiate grape varieties, as well as highly colored fruits (blueberries, bog whortleberry, etc.). The HPLC method has been successfully used to identify hybrid varieties of blueberries [7]. The profiles of anthocyans of old Italian varieties were compared using both reverse-phase highperformance liquid chromatography (RP-HPLC) and mass spectrometry (MS) with laser desorption-ionization and ionization (MALDI-TOF), mass spectrometry (MS) [8]. The identification of peptides by the MALDI-TOF MS method is comparable to the UPLC method [9]. The anthocyanin composition of Brazilian red wines was established using HPLC-UV-Vis to identify wines from different regions [10]. For the quantitative determination of polyphenols in pink wines, a fast, sensitive and selective analysis method was developed using ultra-high-performance liquid chromatography in combination with triple quadrupole mass spectrometry (UHPLC-QqQ-MS) [11]. To establish the identity of red grapes, the relative proportions of anthocyans of the berry skin were proposed as primary samples $[12,13]$. It was found that the anthocyanin profile is characteristic of each variety and allows to conduct chemotaxonomic differentiation of red grapes by several signs of metabolites. Insignificant amounts of pelargonidin $(\mathrm{Pg})-3-\mathrm{O}$-glucoside were found in the skin of Vitis rupestris grapes and some varieties of $V$. vinifera [14]. 
There are significant differences between European and European-Amur grape varieties. $V$. vinifera grapes encode an inactive 5-O-glucosyltransferase isoform truncated at the CTerminus, which, on the contrary, is active in American Vitis species, catalyzing the biosynthesis of 3.5-O-diglucoside anthocyans [15]. Although they are sometimes found in trace amounts in red wines derived from $V$. vinifera, diglucosylated anthocyanins are considered characteristic compounds of grapes other than $V$. vinifera, and are tracked as species-specific markers [16], which is used to differentiate between $V$. vinifera and non- $V$. Vinifera species.

The method developed at BelSU allows to determine the composition of grape anthocyanidins for the best identification of markers of interspecific crossing - 3.5diglucosides (Table 1).

Table 1. Composition of grapes anthocyanin complexes.

\begin{tabular}{|l|c|c|c|c|c|c|c|c|c|}
\hline \multirow{2}{*}{ Anthocyans } & \multicolumn{7}{|c|}{ Proportion of anthocyanins by peak areas on the chromatogram, \% } \\
\cline { 2 - 11 } & $\begin{array}{c}\text { Tsimlyansky } \\
\text { Cherny }\end{array}$ & $\begin{array}{c}\text { Hamburg } \\
\text { Muscat }\end{array}$ & $\begin{array}{c}\text { Krasnostop } \\
\text { Zolotovsky }\end{array}$ & $\begin{array}{c}\text { Cabernet } \\
\text { Sauvignon }\end{array}$ & $\begin{array}{c}\text { Cabernet } \\
\text { Severny }\end{array}$ & $\begin{array}{c}\text { Fioletovy } \\
\text { Rannij }\end{array}$ & Denisovsky & Moldova & Isabella \\
\hline Dp3,5diG & & & & & & & 1.8 & 0,60 & 0,40 \\
\hline Cy3,5diG & & & & & & 0.5 & 0.2 & 0,40 & 0,30 \\
\hline Pt3,5diG & & & & & & & 2.9 & 2,10 & 0,90 \\
\hline Pn3,5diG & & & & & & 5.2 & 4.2 & 12,6 & 0,00 \\
\hline Mv3,5diG & & & & & & & 65.6 & 71,5 & 100,00 \\
\hline & 0 & 0 & 0 & 0 & 0 & 5.7 & 74.7 & 87,2 & 2,6 \\
\hline & & & & & & & & & \\
\hline Dp3G & 28.5 & 8.1 & 13.9 & 7.1 & 1.7 & 4.5 & 1.9 & 0,50 & 26,2 \\
\hline Cy3G & 4.7 & 7 & 2.2 & 0.6 & 0.4 & 22 & 0.3 & 0,50 & 8,20 \\
\hline Pt3G & 14.5 & 7.2 & 13.6 & 5.7 & 2.3 & 3.5 & & 0,30 & 18,6 \\
\hline Pn3G & 3.5 & 37.5 & 4 & 4.9 & 5.1 & 53.6 & 0.4 & 1,80 & 1,60 \\
\hline Mv3G & 27.1 & 34.8 & 44.4 & 58.2 & 63 & 7.1 & 6.2 & 9,70 & 9,50 \\
\hline & 78.3 & 94.6 & 78.1 & 76.5 & 72.5 & 90.7 & 8.8 & 12,8 & 64,1 \\
\hline
\end{tabular}

Dp - delphinidin; Cy - cyanidin; Pt - petunidin; Pn - peonidin; Mv - malvidin; G - glycoside; empty cells - less than $0.1 \%$.

The highest content of anthocyanin compounds is represented by malvidin derivatives, which were 58.2\% (Cabernet Sauvignon variety), 63\% (Cabernet Severny variety), 71.8\% (Denisovsky variety), 81.2\% (Moldova variety), 100\% (Isabella variety). The total content of other forms of malvidin in the varieties Denisovsky and Cabernet Severny was more than $82 \%$ and $85 \%$, respectively. Malvidin derivatives are stable molecules, which gives stability to the wine, due to its resistance to oxidation.

Analyzing the obtained data, we can note identical profiles of anthocyans - varieties of traditional cultivation in the Don region Tsimlyansky Cherny, Krasnostop Zolotovsky, as well as the zoned European variety Hamburg Muscat, and the classic European variety Cabernet Sauvignon, have (or retain) the characteristics of classic Vitis vinifera grapes (there are no 3,5-diglucoside compounds). Such signs are noted in the breeding variety Cabernet Severny. Among them, the Tsimlyansky Cherny variety stands out - it has relatively low methyltransferase activity, which led to an unusually large proportion of delphinidin and petunidin derivatives. Hamburg Muscat differs in that it does not have much pronounced activity of the flavonoid-3',5'-hydroxydase enzyme (the amounts of anthocyans and delphinidin and cyanidin series are comparable) this is quite rare.

In the varieties Fioletovy Rannij, Denisovsky, Moldova, Isabella, the characteristics of other types of grapes are inherited very noticeably, but to varying degrees - they are weakly expressed in Fioletovy Rannij; and they dominate the characteristics of Vitis vinifera in the variety Denisovsky. These characteristics are approximately the same in the Moldova variety. At the same time, the Fioletovy Rannij variety belongs to the cyanidin type. The anthocyanin 
complex of Isabella variety is characterized by a high content of delphinidin anthocyans and a low degree of methylation, which is not typical for traditional Vitis vinifera varieties.

\section{Conclusion}

It was found that the anthocyanin profile makes a significant contribution to the formation of color and fullness of taste. Varietal characteristics of grapes associated with hybridization play a key role. It was found that varieties that are resistant to low temperatures accumulate a greater amount of 3.5 diglucosides from $63 \%$ to $100 \%$ (Cabernet Severny, Denisovsky, Moldova, Isabella). Consequently, the level of anthocyanin glycosides is a distinguishing factor for chemometric analysis of grape varieties. Further detailed analysis of the anthocyanin profile, taking into account geographical origin, will provide data for varietal identification of grapes and wines.

\section{References}

1. M. D. Clark, S. L. Teh, E. Burkness, L. Moreira, G. Watson, L. Yin, W. D. Hutchison, J. J. Luby, Aust. J. Grape Wine Res., 24(3), 292-300 (2018). https://doi.org /10.1111/ajgw.12341

2. L. Yin, M. D. Clark, E. C. Burkness, W. D. Hutchison, J. Integ. Pest Manag., 10(1), 16 (2019). https://doi.org/10.1093/jipm/pmz011

3. E. N. Yakimenko, T. I. Guguchkina, T. A. Nudga, A. V. Prakh, V. M. Redka, Winemaking and viticulture, (6) 30-32 (2013). http://www.foodprom.ru/archive/18journals/vinodelie-i-vinogradarstvo/179-vinodelie-i-vinogradarstvo-6-2013

4. Commission Implementing Regulation (EU) No 314/2012 12 April (2012). http://data.europa.eu/eli/reg_impl/2012/314/2012-04-16

5. R. B. Boulton, V. L. Singleton, L .F. Bisson, R. E. Kunkee, Principles and practices of winemaking (Springer Science \& Business Media, 2013). https://link.springer.com/book/10.1007/978-1-4757-6255-6

6. Z. Liang, Y. Yang, L. Cheng, G. Y. Zhong, Food Chem., 132(2), 730-738 (2012). https://doi.org/10.1016/j.foodchem.2011.11.009

7. S. Y. Wang, H. Chen, M. J. Camp, M. K. Ehlenfeldt, Food Chem., 132(2), 855-864 (2012). https://doi.org/10.1016/j.foodchem.2011.11.050

8. G. Picariello, P. Ferranti, G. Garro, G. Manganiello, L. Chianese, R. Coppola, F. Addeo, Food Chem., 146, 15-22 (2014). https://doi.org/10.1016/j.foodchem.2013.08.140

9. J. Huang, K. H. Wong, S. V. Tay, A. How, J. P. Tam, Front. Plant Sci., 10, 973 (2019). https://doi.org/10.3389/fpls.2019.00973

10. R. H. S. De Andrade, L. S. do Nascimento, G.E. Pereira, F. Hallwass, A. P. S. Paim, Microchem. J., 110, 256-262 (2013). https://doi.org/10.1016/j.microc.2013.04.003

11. M. Lambert, E. Meudec, A. Verbaere, G. Mazerolles, J. Wirth, G. Masson, V. Cheynier, N. Sommerer, $\quad$ Molecules, 20(5), 7890-7914 (2015). https://doi.org/10.3390/molecules20057890

12. J. Zhang, L. Li, N. Gao, D. Wang, Q. Gao, S. Jiang, Analytica Chimica Acta, 662(2), 137-142 (2010). https://doi.org/10.1016/j.aca.2009.12.043

13. M. Figueiredo-González, E. Martínez-Carballo, B. Cancho-Grande, J. L. Santiago, M. C. Martínez, J. Simal-Gándara, Food Chem., 130(1), 9-19 (2012). https://doi.org/10.1016/j.foodchem.2011.06.006

14. M. De Rosso, L. Bavaresco, F. De Marchi, A. Dalla Vedova, A. Panighel, R. Flamini, Acta Hortic., 1082, 223-231 (2015). https://doi.org/10.17660/actahortic.2015.1082.31 
15. C. Ehrhardt, P. Arapitsas, M. Stefanini, G. Flick, F. Mattivi, J. Mass Spectrom., 49(9), 860-869 (2014). https://doi.org/10.1002/jms.3440

16. Y. Yang, J. A. Labate, Z. Liang, P. Cousins, B. Prins, J. E. Preece, M. Aradhya, G. Y. Zhong, Theor. Appl. Genet. 127 2433-2451 (2014). https://doi.org/10.1007/s00122-014-2388-6 